\title{
Characterization of hospital-associated lineages of ampicillin-resistant Enterococcus faecium from clinical cases in dogs and humans
}

\author{
Cindy-Love Tremblay ${ }^{1}$, Audrey Charlebois ${ }^{1}$, Luke Masson $^{2}$ and Marie Archambault ${ }^{1 *}$ \\ ${ }^{1}$ Department of Pathology and Microbiology, Faculty of Veterinary Medicine, University of Montreal, CRIPA Research Group, Quebec, QC, Canada \\ 2 Biotechnology Research Institute, National Research Council of Canada, Montreal, OC, Canada
}

Edited by:

Axel Cloeckaert, Institut National de la Recherche Agronomique, France

Reviewed by:

Carla Novais, Porto University,

Portugal

Freddy Haesebrouck, Ghent

University, Belgium

\section{*Correspondence:}

Marie Archambault, Department of Pathology and Microbiology, Faculty of Veterinary Medicine, University of Montreal, CRIPA Research Group, 3200 Sicotte Street,

Saint-Hyacinthe, Quebec,

OC J2S 7C6, Canada

e-mail:marie.archambault@

umontreal.ca
Ampicillin-resistant Enterococcus faecium (ARE) has rapidly emerged worldwide and is one of the most important nosocomial pathogens. However, very few reports are available on ARE isolates from canine clinical cases. The objective of this study was to characterize ARE strains of canine clinical origin from a veterinary teaching hospital in Canada and to compare them with human strains. Ten ARE strains from dogs and humans were characterized by multilocus sequence typing (MLST), pulsed field gel electrophoresis (PFGE), antibiotic susceptibility and biofilm activities, presence of rep-families, CRISPRcas and putative virulence genes. All ARE strains $(n=10)$ were resistant to ciprofloxacin and lincomycin. Resistances to tetracycline $(n=6)$, macrolides $(n=6)$, and to high concentrations of gentamicin, kanamycin and streptomycin $(n=5)$ were also observed. Canine ARE isolates were found to be susceptible to vancomycin whereas resistance to this antibiotic was observed in human strains. Ampicillin resistance was linked to PBP5 showing mutations at 25 amino acid positions. Fluoroquinolone resistance was attributable to ParC, GyrA, and GyrB mutations. Data demonstrated that all canine ARE were acm (collagen binding protein)-positive and that most harbored the efa $A_{f m}$ gene, encoding for a cell wall adhesin. Biofilm formation was observed in two human strains but not in canine strains. Two to five rep-families were observed per strain but no CRISPR sequences were found. A total of six STs $(1,18,65,202,205$, and 803) were found with one belonging to a new ST (ST803). These STs were identical or closely related to human hospital-associated lineages. This report describes for the first time the characterization of canine ARE hospital-associated strains in Canada and also supports the importance of prudent antibiotic use in veterinary medicine to avoid zoonotic spread of canine ARE.

Keywords: Enterococcus faecium, clinical cases, antibiotic resistance, virulence, plasmid, hospital-associated community-associated, MLST

\section{INTRODUCTION}

Multiresistant Enterococcus faecium has become one of the most important nosocomial pathogens, causing increasing numbers of nosocomial infections worldwide (Willems et al., 2012). They now represent up to one-third of enterococcal infections (Willems and Van Schaik, 2009). A multilocus sequence typing (MLST) study of E. faecium isolates revealed the existence of a distinct genetic subpopulation associated with nosocomial infections which was named clonal complex 17 (CC17) (Willems et al., 2011). Recently, other studies (Van Schaik and Willems, 2010; Van Schaik et al., 2010; De Regt et al., 2012; Willems et al., 2012) have indicated that these hospital-associated $E$. faecium (HA E. faecium) did not evolve from a single founder [i.e., sequence type (ST) 17] as there are now several founders identified. More recently, a Bayesian population genetic analysis revealed that HA E. faecium could be divided into three lineages originating from STs 17, 18 and 78, all ampicillin resistant and with variable resistance phenotypes to other antibiotics (Willems et al., 2012).
Genome-wide analyses have shown that HA ARE have a genetic repertoire distinct from E. faecium strains that asymptomatically colonize the intestinal tract of both humans and animals in the community (Leavis et al., 2007; Van Schaik et al., 2010) and are found only sporadically among non-hospital isolates (Willems et al., 2011). However, previous studies around the world (Damborg et al., 2008, 2009; De Regt et al., 2008, 2012; Ossiprandi et al., 2008; Jackson et al., 2009; Kwon et al., 2012) have revealed that healthy dogs are known community reservoirs where some of these typical hospital clones seem to reside. Furthermore, HA ARE have been recovered from clinical cases of urinary tract infections in canines from the U.S. (Simjee et al., 2002), Korea (Kwon et al., 2012) and Denmark (Damborg et al., 2008) and from feces of canines leaving the intensive care unit of an American veterinary medicine teaching hospital (Ghosh et al., 2011). In general, only limited data is available on lineages and genotypic content of HA ARE from canine clinical isolates.

A recent report from Canadian human cases of HA ARE (McCracken et al., 2013) has indicated that a shift in ST has 
occurred after 2006 and that around that time bacteraemia rates began to rise in central and western Canada, suggesting a possible correlation. Prior to 2006, predominant types included ST154, ST16, ST17 and ST80 and after 2006, ST18, ST203, ST412 and ST584 became predominant in Canada (McCracken et al., 2013). In Canada, no data is available on ARE isolates from dogs with ST lineages causing nosocomial infections in humans. Thus, the goal of this study was to characterize canine ARE clinical isolates from Québec, Canada and to determine their STs. Also, HA ARE strains of human origin were used for comparison to assess possible genetic relationships between the two sets of strains. This study underscores the importance of canines as potential reservoirs of multi-drug resistant HA ARE.

\section{MATERIALS AND METHODS \\ BACTERIAL ISOLATES AND IDENTIFICATION}

Ten E. faecium strains were used in this study (Table 1). Dog' strain isolation criteria were the presence of a relatively recent (2007-2012) clinical infection, isolation in pure culture, and PCR identification as E. faecium species. Based on these criteria only five canine E. faecium isolates were recovered over this period from the diagnostic laboratory of the Faculty of Veterinary Medicine at the University of Montreal and these were from UTI, wounds and cholangiohepatitis infections. The human isolates $(n=5)$ were provided by the "Centre de Recherche Hospitalier de l'Université Laval (CRCHUL)" and randomly chosen from a culture collection of E. faecium from hospitalized patients over the same period. Some of the human isolates (CCRI no. 18581, 16717 and 16354) were from colonization/surveillance studies of hospitalized patients. All isolates were identified by multiplex PCR assay using species-specific primer sets for the $d d l$ faecium ( $d d l$ F-5'TTGAGGCAGACCAGATTGACG3' and $d d l$ R5'TATGACAGCGACTCCGATTCC $3^{\prime}$ ) identification gene as previously described (Tremblay et al., 2011). E. faecium HA-56038 was used as a positive control.

\section{ANTIBIOTIC SUSCEPTIBILITY TESTING}

Isolates were tested for MIC using the Sensititre plate CMV3AGPF (Trek ${ }^{\mathrm{TM}}$ Diagnostic System Ltd, Cleveland, $\mathrm{OH}$ ) according to the Clinical and Laboratory Standards Institute (CLSI, M31-A3 and M100-S20) guidelines (Clinical and Laboratory Standards Institute, 2008, 2010). Ciprofloxacin and ampicillin susceptibilities were further analyzed by standard broth macrodilution method (CLSI, M31-A3 and M100-S20). Breakpoints from CLSI and the Canadian Integrated Program for Antimicrobial Resistance Surveillance (CIPARS) were used (Anonymous, 2008). Staphylococcus aureus ATCC29213 and Enterococcus faecalis ATCC29212 were used as control strains.

\section{PFGE AND MLST}

Isolates were analyzed for clonal diversity by pulsed-field gel electrophoresis (PFGE) after SmaI (New England Biolabs, Inc., Beverly, Ma, USA) digestion as described by Garcia-Migura et al. (2005). Digested DNA was electrophoresed as previously described (Vankerckhoven et al., 2008). Computer analysis of PFGE banding patterns was performed with Bionumerics Version 6.5 software (Applied Maths, Austin, TX, USA). Banding pattern similarities were analyzed by the Dice coefficient, and cluster analysis was performed by the unweighted-pair group method using average linkages (UPGMA). PFGE types were determined as $=80 \%$ similarity. MLST was based on seven E. faecium housekeeping genes (atpA, ddl, gdh, purk, gyd, pstS, and adk). Different sequences were assigned allele numbers, and different allelic profiles were assigned STs based on the MLST database (http://www.mlst.net/databases/). Analysis was performed using the eBURST version 3 algorithm implemented as a Java applet at http://eburst.mlst.net.

\section{DNA MICROARRAYS}

Microarray hybridization experiments were performed as previously described (Champagne et al., 2011). This enterococcal virulence microarray was developed (Diarra et al., 2010) at the National Research Council in Montreal and carries 70 taxonomic probes for species identification as well as 15 virulence factors, and 173 antibiotic resistance probes for a total of 262 probes. The microarray was used for the detection of putative target genes. Briefly, bacterial DNA isolated from single colonies was labeled with Cy5-dCTP (GE Healthcare, Little Chalfont, UK). Hybridization, washing, scanning, image processing, scoring, and data analysis were done as previously described (Champagne et al., 2011). Arrays were scanned by a ScanArray Express microarray Scanner (Packard Biosciences, Billerica, MA, USA). Oligonucleotide spots with a signal-tonoise fluorescence ratio above 3 were considered positive. Positive microarray results were confirmed by PCR with specific primers for the following genes tet $(\mathrm{M}), \operatorname{tet}(\mathrm{O}), \operatorname{tet}(\mathrm{L}), \operatorname{erm}(\mathrm{B}), \operatorname{agg}$ and esp (Table 2). Since erm(AM) and erm(B) shared over $80 \%$ similarity and are perfectly correlated, they were considered as the same in this study as previously proposed (Roberts et al., 1999).

\section{PCR DETECTION OF VIRULENCE AND ANTIBIOTIC RESISTANCE GENES}

PCR amplifications of virulence genes acm and hyl and of the quinolone resistance-determining regions (QRDR) genes were performed as previously described (Nallapareddy et al., 2003; Vankerckhoven et al., 2004; Billstrom et al., 2008; Werner et al., 2010). The $\mathrm{N}$-terminal and C-terminal regions of the pbp5 gene were amplified by PCR (Aarestrup et al., 2002; Poeta et al., 2007). Both strands of the purified QRDRs and $p b p 5$ amplicon products were sequenced. Sequences of gyr $A / B$ and $p a r C / E$ were compared with the E. faecium DO genome (GenBank accession no. CP003583) whereas sequences of the $\mathrm{C}$ - and N-terminal regions of $p b p 5$ gene were compared with $p b p 5$ gene reference sequence (GenBank accession no. X84860).

\section{PCR FOR REPA GENES (PLASMID FAMILIES)}

All isolates were screened for rep-like sequences by PCR as previously described (Jensen et al., 2010) with few modifications (Table 2). Briefly, fourteen different rep-family plasmids $\left(r e p_{1-2}, r e p_{4}, r e p_{6}, r e p_{8-9}, r e p_{11}, r e p_{13-15}, r e p_{16-18}\right.$ and rep Unique $)$ were tested for their presence in E. faecium isolates. The PCR amplified and sequenced amplicons from selected strains (E. faecium strain no. 07-5598, M2146-08, 18581 and 


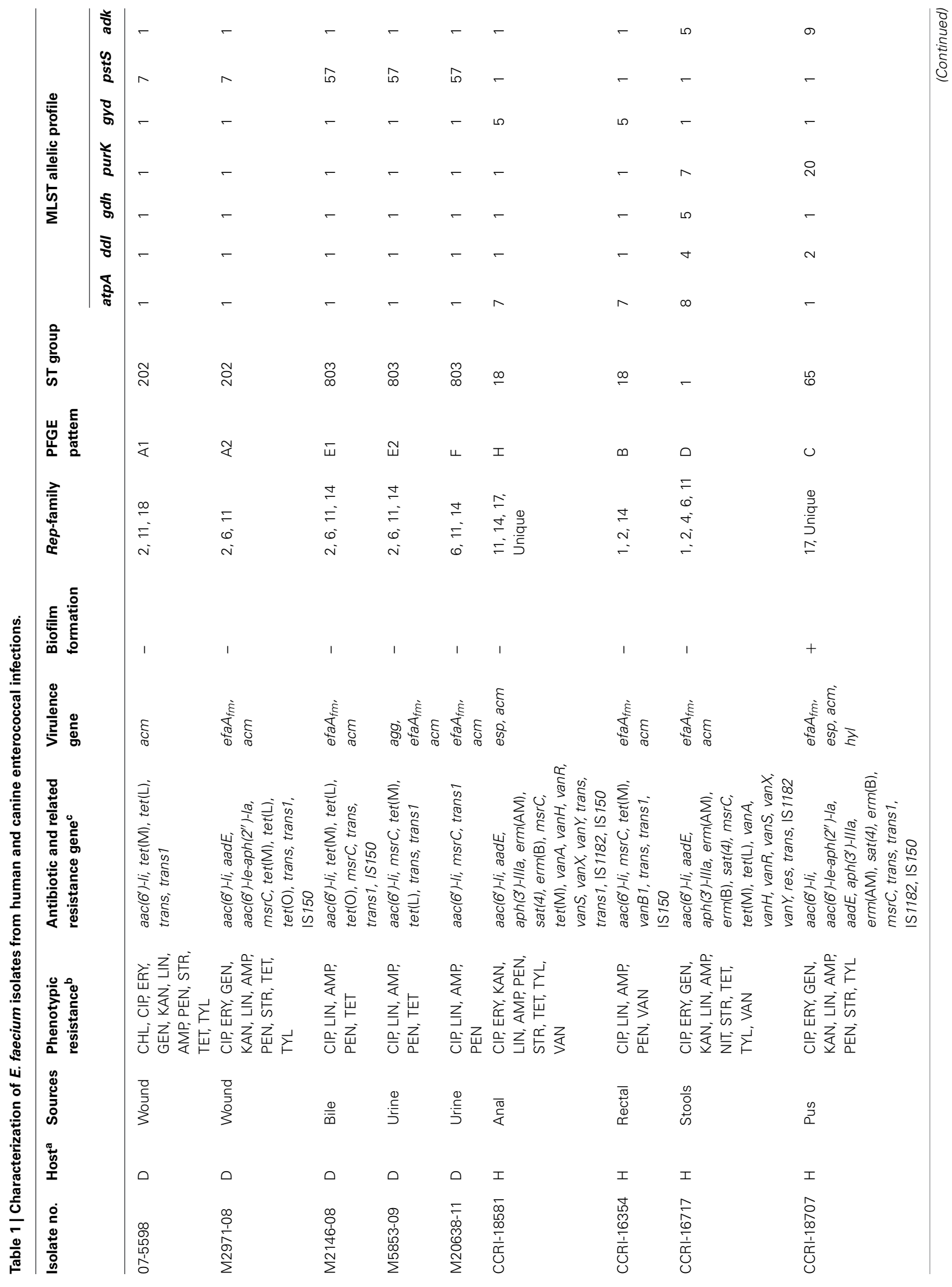


16717) from this study were used as positive controls for $r e p_{1-2}, r e p_{4}, r e p_{6}, r e p_{14}, r e p_{17-18}$ and repunique whereas control strains for $r e p_{8-9}, r e p_{11}, r e p_{13}$, and rep $p_{15-16}$ were from a previous study (Tremblay et al., 2012). The families' rep $p_{3}, r e p_{5}$, $r e p_{7}, r e p_{10}$, and rep 19 could not be tested because no positive PCR products were obtained and no control strains were available.

\section{DETECTION OF CRISPR-cas}

The CRISPR1-cas and CRISPR3-cas loci were screened by PCR as previously described (Palmer and Gilmore, 2010) with slight modifications. Briefly, the PCR reactions were performed in a total of $50 \mu \mathrm{l}$, using $80 \mathrm{pmol}$ of each primer, $1.5 \mathrm{mM} \mathrm{MgCl}_{2}$, $10 \mathrm{mM}$ each of dNTPs, $2 \mathrm{U}$ of Taq DNA, 1X Buffer mix (New England Biolabs) and sample DNA. Amplification reactions were carried out using a Whatman Biometra thermocycler (Montreal Biotech Inc, Québec, Canada) programmed as follows: an initial denaturation step of $94^{\circ} \mathrm{C}$ for $2 \mathrm{~min}, 30$ cycles of denaturation at $94^{\circ} \mathrm{C}$ for $1 \mathrm{~min}$, annealing for $1 \mathrm{~min}$ and extension at $72^{\circ} \mathrm{C}$ for $1 \mathrm{~min}$, followed by a final elongation at $72^{\circ} \mathrm{C}$ for $5 \mathrm{~min}$. For visualization, $5 \mu \mathrm{l}$ of the PCR reaction were subjected to electrophoresis in $1.2 \%$ agarose gel stained with ethidium bromide. A 100 bp ladder (TrackIt, Invitrogen, Ontario, Canada) was used as a marker. Enterococcus faecalis strain no. 02-A701 and 06-6225 were used as positive controls.

\section{BIOFILM FORMATION}

Isolates were inoculated in tryptic soy broth (TSB) supplemented with $1 \%$ glucose in 96 well microtiter plates (Fisher scientific) for bacterial growth and biofilm formation as described elsewhere (Zoletti et al., 2011). Biofilm was quantified using crystal violet staining method as described by Zoletti et al. (2011). Staphylococcus epidermidis ATCC 35984 (biofilm producer) and wells containing uninoculated medium were used as controls. ODs were obtained using a microplate reader Biotek Synergy HT (Bio-tek Instruments Inc., Winooski, VT, USA) at a wavelength of $570 \mathrm{~nm}$. Analyses were based on two different experiments where isolates were tested in triplicate. The quantification of biofilm formation in microtiter plates was performed as previously described (Stepanovic et al., 2000, 2007). Briefly, strains were divided into the following categories: no biofilm producer $(-)$, weak biofilm producer $(+)$, moderate biofilm producer $(++)$ and strong biofilm producer $(+++)$, based upon the previously calculated $\mathrm{OD}$ values: $\mathrm{OD} \leq \mathrm{ODc}=$ no biofilm producer; $\mathrm{ODc}<\mathrm{OD} \leq 2 \mathrm{X}$ ODc $=$ weak biofilm producer; $2 \mathrm{X}$ $\mathrm{ODc}<\mathrm{OD} \leq 4 \mathrm{X}$ ODc $=$ moderate biofilm producer; $4 \mathrm{X}$ ODc $<\mathrm{OD}=$ strong biofilm producer. ODc is defined as three standard deviations (SD) above the mean $\mathrm{OD}$ of the negative control.

\section{STATISTICAL ANALYSIS}

A chi-square exact test was used to examine the association between isolate, origin, antibiotic resistance, virulence genes, biofilm formation, plasmid families and CRISPR genes. Statistical analyses were carried out using SAS software v. 9.2 (SAS Institute Inc., Cary, N.C., USA). The level of statistical significance was set at 0.05 . 
Table 2 | Primers and conditions used in PCR for confirmation of microarray results and for rep-like genes identification.

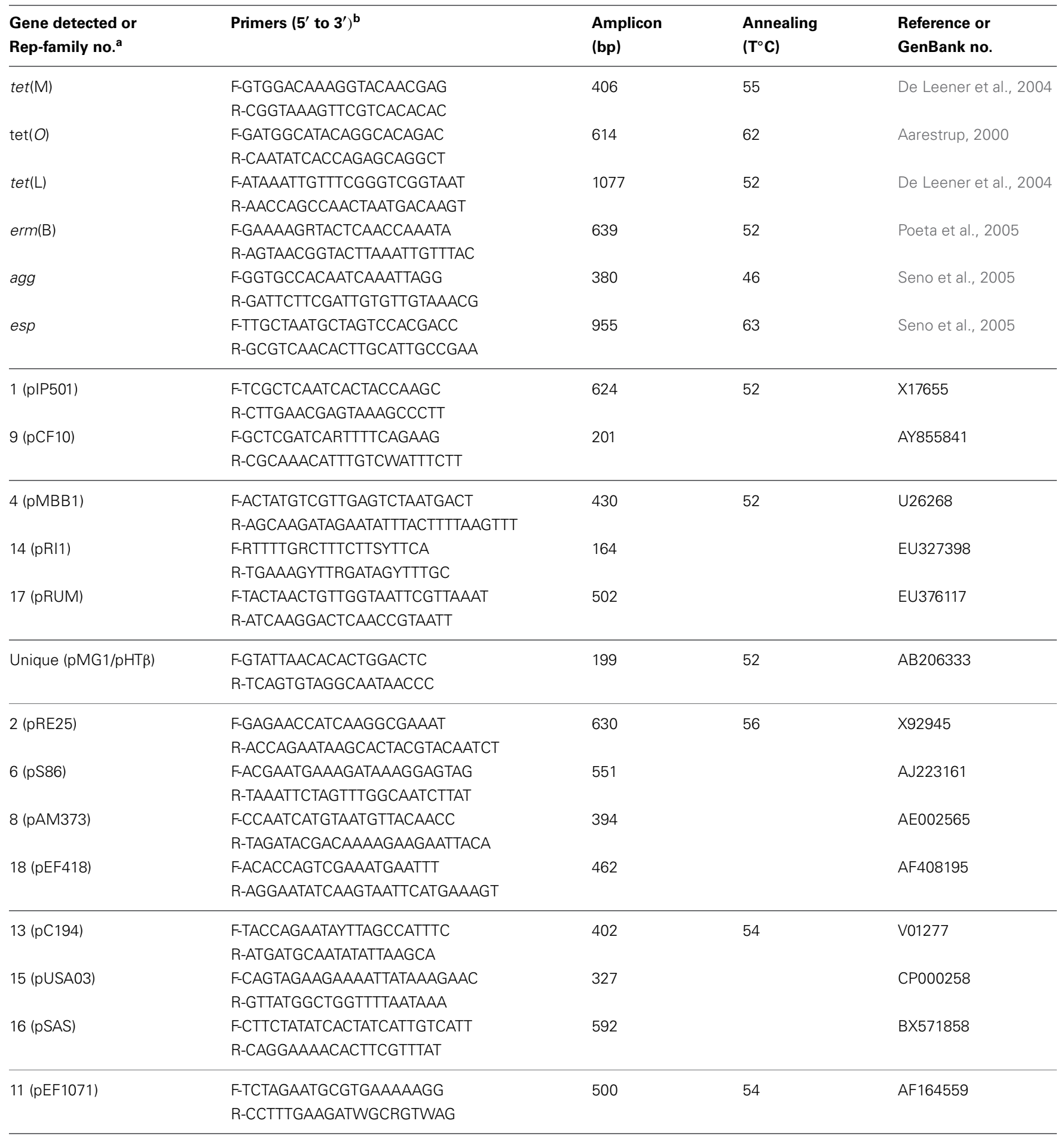

${ }^{a}$ Rep-family numbers are associated with plasmid in parenthesis.

${ }^{b} F$, forward; $R$, reverse.

\section{RESULTS}

\section{MLST AND PFGE}

MLST allelic profiles are presented in Table 1. A total of six STs were found among the E. faecium isolates, ST1 $(n=1), \operatorname{ST} 18(n=$ $2)$, ST65 $(n=1), \operatorname{ST} 202(n=2)$, ST205 $(n=1)$ and one novel,
ST803 (isolates M2146-08, M5853-09 and M20638-11) (Table 1). Canine ARE belonged to ST202 $(n=2)$ and ST803 $(n=3)$ both SLV of ST17. Human clinical isolates belonged to ST65 $(n=$ 1), a singleton known to be found only among clinical strains (Werner et al., 2011), and ST205 ( $n=1$ ), a SLV of ST17 (Table 1). 
Human surveillance isolates belonged to ST18 $(n=2)$, and ST1 $(n=1$, linked to CC1). Therefore, all these STs were linked to HA-ARE except for ST1 which was shown to belong to a cluster containing primarily isolates from calves in the Netherlands (http://efaecium.mlst.net/). Following genomic SmaI digestion and PFGE, the E. faecium isolates $(n=10)$ of human and canine origins produced ten macro-restriction patterns clustered into eight PFGE types, termed A through $\mathrm{H}$ (Table 1). Canine E. faecium isolates of subtypes $\mathrm{A}$ and $\mathrm{E}$ were $\geq 80 \%$ similar whereas the remaining $E$. faecium isolates were considered unrelated ( $\leq 80 \%)$. The E. faecium PFGE types B and $\mathrm{H}$ were set as a same group by MLST (ST18) whereas the new ST803 was grouped as PFGE types $\mathrm{E}$ and $\mathrm{F}$ (Table 1).

\section{ANTIBIOTIC RESISTANCE}

Chloramphenicol, ciprofloxacin, erythromycin, lincomycin, tylosin, gentamicin, kanamycin, streptomycin, penicillin, ampicillin, and tetracycline resistances were observed in E. faecium clinical isolates of canine origin with no resistance observed to daptomycin, linezolid, nitrofurantoin, quinupristin/dalfopristin, vancomycin and tigecycline (Tables 1, 3). Resistances to ciprofloxacin, erythromycin, lincomycin, tylosin, gentamicin, kanamycin, streptomycin, nitrofurantoin, penicillin, ampicillin, tetracycline and vancomycin but not to chloramphenicol, daptomycin, linezolid, quinupristin/dalfopristin and tigecycline were observed in human E. faecium clinical isolates (Tables 1, 3). All E. faecium isolates were resistant to ampicillin, ciprofloxacin and lincomycin. Seven isolates were considered as high-level ciprofloxacin-resistant (MICs of $>16 \mu \mathrm{g} / \mathrm{ml}$ ) whereas nine isolates showed high-level ampicillin resistance (MICs of $\geq$ $256 \mu \mathrm{g} / \mathrm{ml}$ ) (Table 3). Also, erythromycin resistance $(n=6)$ was positively associated $(p$-value $<0.05)$ with aminoglycoside resistance $(n=6)$, whereas ciprofloxacin resistance $(n=10)$ correlated ( $p$-value $<0.05)$ with ampicillin $(n=9)$ resistances. All vancomycin resistant E. faecium $(n=3)$ isolates were of human origin.

\section{MICROARRAY AND PCR ANALYSIS OF VIRULENCE AND ANTIBIOTIC RESISTANCE GENES}

Virulence and antibiotic resistant genotypes are presented in Table 1. Results demonstrated all canine ARE isolates were acmpositive but were negative for esp and $h y l$ genes. The majority of these isolates were shown to harbor $e f a A_{f m}$ gene, encoding for a cell wall adhesin. One canine ARE isolate also had the agg gene encoding for an aggregation substance of pheromone-responsive plasmid. The $e f a A_{f m}$ gene was detected in all human isolates but one. The two human clinical isolates (CCRI-18707 and 18231) were also positive for the glycosyl hydrolase gene ( $h y l$ ). Acquisition of multiple antibiotic resistance genes was observed ranging from 2 to 14 per isolate. Correlation between MICs and the presence of resistance genes has indicated that tetracycline resistance was attributable to tet $(\mathrm{M})(n=2)$; tet $(\mathrm{M})$ and tet $(\mathrm{L})(n=3)$; and $\operatorname{tet}(\mathrm{M}), \operatorname{tet}(\mathrm{L})$ and $\operatorname{tet}(\mathrm{O})(n=2)$. Resistance to erythromycin, lincomycin and tylosin could be explained by the presence of $m s r C$, erm (AM)/ erm(B) in all strains with the exception of one (07-5598). Streptomycin resistance was associated with the aadE gene in all strains except one (075598). Kanamycin resistance was explained by aph $\left(3^{\prime}\right)-I I I a$ in all strains except two (07-5598 and M2971-08) whereas gentamicin resistance was attributable to $a a c\left(6^{\prime}\right)-I e-a p h\left(2^{\prime}\right)-I a$ in all strains but two (07-5598 and CCRI-16717). Chloramphenicol resistance $(n=1)$ could not be explained because both cat and floR genes were absent in the two canine ARE resistant isolates. The gene $\operatorname{aac}\left(6^{\prime}\right)$-Ii is intrinsic in E. faecium and confers

Table 3 | Antibiotic resistance of E. faecium clinical isolates from humans and dogs based on MICs.

\begin{tabular}{|c|c|c|c|c|c|c|c|c|c|c|c|c|c|c|c|c|c|c|c|}
\hline \multirow{2}{*}{ Antibiotic agent } & \multicolumn{17}{|c|}{ Number of isolates at a MIC $(\mu \mathrm{g} / \mathrm{ml})$ of $^{\mathrm{b}}$} & \multicolumn{2}{|c|}{$\%$ Resistant isolates (b) } \\
\hline & 0,06 & 0,12 & 0,25 & 0,5 & 1 & 2 & 4 & 8 & 16 & 32 & 64 & 128 & 256 & 512 & 1024 & 2048 & 4096 & Human & Dog \\
\hline Chloramphenicol & & & & & & & & 8 & 1 & 1 & & & & & & & & $0(0)$ & $20(1)$ \\
\hline Daptomycin & & & & & & 7 & 3 & & & & & & & & & & & $0(0)$ & $0(0)$ \\
\hline Erythromycin & & & & & & 2 & 2 & & 6 & & & & & & & & & $80(4)$ & $40(2)$ \\
\hline Gentamicin & & & & & & & & & & & & 5 & & & & 5 & & $60(3)$ & $40(2)$ \\
\hline Kanamycin & & & & & & & & & & & & 4 & & & & 6 & & $80(4)$ & $40(2)$ \\
\hline Lincomycin & & & & & & & & & 10 & & & & & & & & & $100(5)$ & $100(5)$ \\
\hline Linezolid & & & & & & 9 & 1 & & & & & & & & & & & $0(0)$ & $0(0)$ \\
\hline Ciprofloxacin $^{\mathrm{a}}$ & & & & & & & 1 & 2 & & & 1 & 2 & & 4 & & & & $100(5)$ & $100(5)$ \\
\hline Nitrofurantoin & & & & & & & & & & 1 & 8 & 1 & & & & & & $20(1)$ & $0(0)$ \\
\hline Ampicillin $^{\mathrm{a}}$ & & & & & & & & & & & 1 & & 3 & 6 & & & & $100(5)$ & $100(5)$ \\
\hline Penicillin & & & & & 1 & & & & & 9 & & & & & & & & $80(4)$ & $100(5)$ \\
\hline Streptomycin & & & & & & & & & & & & & & 4 & 1 & 1 & 4 & $80(4)$ & $40(2)$ \\
\hline $\begin{array}{l}\text { Quinupristin/ } \\
\text { dalfopristin }\end{array}$ & & & & 6 & 3 & 1 & & & & & & & & & & & & $0(0)$ & $0(0)$ \\
\hline Tetracycline & & & & & 4 & & & & & 1 & 5 & & & & & & & $40(2)$ & $80(4)$ \\
\hline Tylosin & & & & & & 3 & 1 & & & & 6 & & & & & & & $80(4)$ & $40(2)$ \\
\hline Vancomycin & & & & 2 & 5 & & & & & & 3 & & & & & & & $60(3)$ & $0(0)$ \\
\hline Tigecyline & 5 & 5 & & & & & & & & & & & & & & & & $0(0)$ & $0(0)$ \\
\hline
\end{tabular}

a Ciprofloxacin and ampicillin MICs from the standard broth macrodilution method.

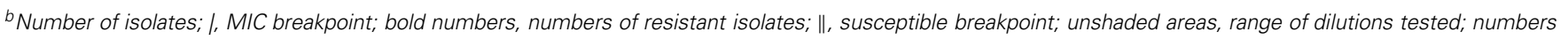
in the shaded area, isolates with MICs greater than the highest tested concentrations. 
resistance to low-level aminoglycosides. Also, the transposase genes trans and trans1 (both GenBank accession no. AF516335) associated with transposons Tn1546 and Tn5405-like on the plasmid pUW786 carrying multiresistance gene cluster were identified in many isolates $(n=9)$. A correlation $(p$-value $<0.05)$ was observed between aadE (high-level streptomycin resistance), aph (3')-IIIa, (aminoglycoside resistance), sat(4) (streptothricin acetyltransferase) and IS1182 transposase gene (also associated with plasmid pUW786) in human isolates of E. faecium (Diarra et al., 2010). The antibiotic resistance genes erm(AM)/erm(B) (macrolide-lincosamide-streptogramin $\mathrm{B}, \mathrm{MLS}_{b}$ ), aadE, sat(4), $a p h\left(3^{\prime}\right)$-IIIa were significantly $(p$-value $<0.05)$ associated with human isolates. Positive associations $(p$-value $<0.05)$ were observed between trans1 and IS150 transposase genes, aac $\left(6^{\prime}\right)$ $I e-a p h\left(2^{\prime \prime}\right)$-Ia (encoding for a bi-functional aminoglycosidemodifying enzyme) and erm(AM)/erm(B). No beta-lactamase genes were detected in this study.

\section{SCREENING FOR gyrA/B AND paRC/E MUTATIONS}

Enterococcus faecium isolates spanned a range of ciprofloxacin MICs from $4 \mu \mathrm{g} / \mathrm{ml}$ to $>256 \mu \mathrm{g} / \mathrm{ml}$ with seven isolates considered as high-level ciprofloxacin-resistant (MICs of $>16 \mu \mathrm{g} / \mathrm{ml}$ ) (Table 3). High-level ciprofloxacin resistance was attributable to ParC (Ser80 $\rightarrow$ Arg, Ile or Asp; and Asn73 $\rightarrow$ Asp) and GyrA (Ser83 $\rightarrow$ Arg, Tyr, or Ile; Met127 $\rightarrow$ Trp; and Glu87 $\rightarrow$ Lys) mutations (Table 4). All high-level ciprofloxacin-resistant isolates had mutations in both GyrA (Ser83 $\rightarrow$ Arg or Tyr or Ile) and ParC (Ser80 $\rightarrow$ Arg or Ile or Asp). Corresponding fragments of subunits B (parE/gyrB) were also investigated. Two isolates demonstrated mutations in GyrB (Asp436 $\rightarrow$ Asn, Leu371 $\rightarrow$ Trp and Pro455 $\rightarrow$ Ser) whereas no changes in ParE were detected (Table 4). Isolates with MICs of $<16 \mu \mathrm{g} / \mathrm{ml}$ did not harbor mutational changes.

\section{SEOUENCE ANALYSIS OF pbp5}

Nine isolates showed high-level ampicillin resistance (MICs of $\geq 256 \mu \mathrm{g} / \mathrm{ml}$ ) with all canine ARE being high-level. Both the Nterminal and C-terminal regions were analyzed and revealed that
PBP5 contained 25 amino acid changes, as shown in Table 5. The insertion of aspartic acid at position $466^{\prime}$ was mostly observed in isolates of animal origin. Alleles were designated 1-5 based on important amino acid substitutions in the $\mathrm{C}$-terminal region with none showing $100 \%$ identity with the reference sequence (GenBank accession no. X84860). The same pbp5 alleles (alleles 1 and 2) were observed in clonal isolates with PFGE patterns A1 and $\mathrm{A} 2$ and $\mathrm{E} 1$ and $\mathrm{E} 2$.

\section{repA GENES (PLASMID FAMILIES)}

Nine different rep-family plasmid genes $\left(r e p_{1-2}, r e p_{4}, r e p_{6}, r e p_{11}\right.$, $r e p_{14}, r e p_{17-18}$ and rep Unique $)$ were detected in E. faecium isolates (Table 1). The predominant rep-family among E. faecium isolates was rep 11 (pEF1071) with seven isolates. Other repfamilies were also observed: rep 1 (pIP501) $(n=2), r e p_{2}$ (pRE25) $(n=6), r^{2} p_{4}(\mathrm{pMBB} 1)(n=1)$, rep $_{6}(\mathrm{pS} 86)(n=5)$, rep $_{14}(\mathrm{pRI} 1)$ $(n=5), r_{17}(\mathrm{pRUM})(n=3), \operatorname{rep}_{18}(\mathrm{pEF} 418)(n=1)$ and repunique $(\mathrm{pUB} 101)(n=3)$. Overall, rep $_{11}$ and rep $p_{6}$ families were significantly ( $p$-value $<0.05$ ) associated with isolates of canine origin. The families' $r e p_{8-9}, r e p_{13}$, and $r e p_{15-16}$ were not detected.

\section{CRISPR-cas GENES}

To determine whether there is an association between CRISPR elements and plasmid family genes, virulence and/or antibiotic resistance genes, CRISPR-cas genes were investigated by PCR. Because potential sequence divergence among $\operatorname{csn} 1$ genes, an internal region of CRISPR-cas locus-specific genes, may lead to false-negative PCR results, isolates with negative PCR results were further screened with primers flanking the conserved locations of the CRISPR1-cas and CRISPR3-cas loci, between homologues of EF0672-EF0673 and EF1760-EF1759, respectively, as compared with the E. faecalis genome V583 (Palmer and Gilmore, 2010). According to Palmer and Gilmore (2010), one CRISPR-cas locus was identified in three E. faecium genomes. However, this locus could not be detected in our ten ARE strains. No significant correlations could be made with the absence of antibiotic resistance, virulence, and plasmid family genes due to low number of isolates.

Table 4 | Mutations in $g y r A / B$ and parC of clinical E. faecium isolates with their corresponding ciprofloxacin MIC.

\begin{tabular}{|c|c|c|c|c|c|}
\hline \multirow[t]{2}{*}{ Ciprofloxacin MIC ( $\mu \mathrm{g} / \mathrm{mI})$} & \multirow[t]{2}{*}{ Isolate no. } & \multirow[t]{2}{*}{ Host $^{a}$} & \multicolumn{3}{|c|}{ Amino acid ${ }^{b}$ mutation in gene (codon) } \\
\hline & & & gyrA & gyrB & parC \\
\hline 4 & M2146-08 & $\mathrm{D}$ & None & None & None \\
\hline 8 & M5853-09 & $\mathrm{D}$ & None & None & None \\
\hline 8 & CCRI-16717 & $\mathrm{H}$ & None & None & None \\
\hline 64 & M20638-11 & $\mathrm{D}$ & I (83) & $N(436)$ & $\mathrm{R}(80)$ \\
\hline 128 & $07-5598$ & $D$ & Y (83), W (127) & None & I (80) \\
\hline 128 & CCRI-18231 & $\mathrm{H}$ & $\mathrm{K}(87)$ & None & I (80), D (73) \\
\hline$>256$ & M2971-08 & $\mathrm{D}$ & Y (83) & None & I (80) \\
\hline$>256$ & CCRI-18581 & $\mathrm{H}$ & Y (83) & None & $\mathrm{R}(80)$ \\
\hline$>256$ & CCRI-16354 & $\mathrm{H}$ & Y (83) & W (371), S (455) & I (80) \\
\hline$>256$ & CCRI-18707 & $\mathrm{H}$ & R (83) & None & I (80) \\
\hline
\end{tabular}

${ }^{a} D$, dogs; H, humans.

${ }^{b} D$, aspartic acid; I, isoleucine; $K$, lysine; $N$, asparagine; $R$, arginine; $S$, serine; $W$, tryptophan; $Y$, tyrosine. 


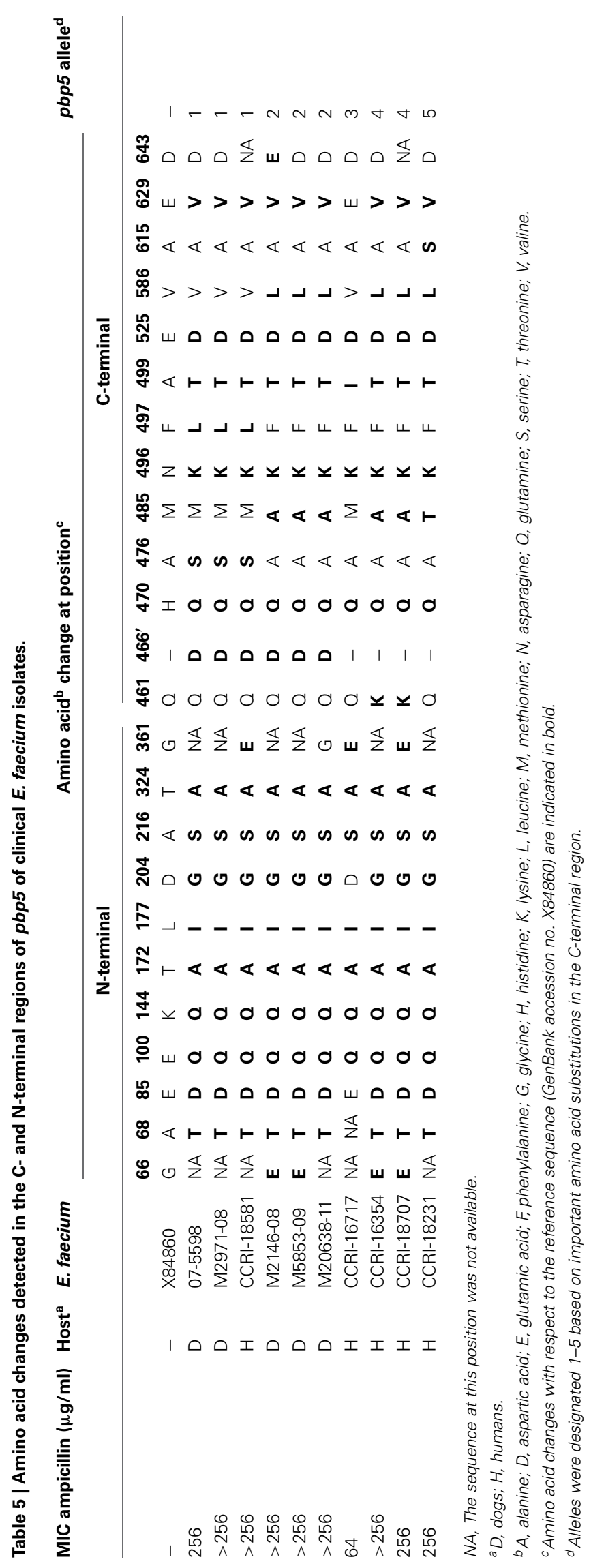

\section{BIOFILM FORMATION}

Both isolates producing biofilm were recovered from infections, one weak and one strong both harboring the esp gene (Table 1), contrasting with those from surveillance. However, one ARE isolate which colonized a hospitalized patient was positive for the esp gene and did not produce a biofilm.

\section{DISCUSSION}

To the best of our knowledge, we describe for the first time, the characterization of ARE strains of canine origin from Canada with STs identical (ST202) or closely related (ST803) to human hospital-associated lineages. Colonization by major clones is relatively rare in healthy humans (De Regt et al., 2012). The presence in canine clinical cases of identical or closely related ARE clones currently involved in the nosocomial epidemiology supports the hypothesis that, cross-transmission between humans and dogs may potentially occur. This is also why it was decided to fully characterized these dog strains and compare them with human strains from Canada. In canines, reports have indicated that ARE most frequently were of ST266 origin but that a variety of STs associated with human clinical infections could also be found (Damborg et al., 2008, 2009; Ghosh et al., 2011; De Regt et al., 2012). These findings, along with the current study, present evidence of some genotypic concordance, based on MLST, between hospital clones of human origin and community ARE from clinical cases of dogs, indicating that these isolates are likely evolutionarily linked. This has also been previously suggested by a phylogenomic analysis of two dog strains and seven sequenced E. faecium genomes derived from humans (De Regt et al., 2012). Similar to a study on Dutch canine ARE isolates (De Regt et al., 2012), canine ARE isolates in our study were not an "exact copy" to those in the circulating Canadian hospital reservoir as none of the human predominant types in Canada (McCracken et al., 2013) were identified in these isolates. This could also be because the number of isolates of this study was limited.

In humans, the emergence of high-level ampicillin resistance, specifically in US hospitals in the early 1980s, preceded the epidemic rise of vancomycin resistance, which occurred in the 1990s, explaining why virtually all vancomycin-resistant enterococci (VRE) recovered from nosocomial infections in humans are also ampicillin resistant (Grayson et al., 1991; Iwen et al., 1997). In this study, the transposase genes trans and trans1, associated with $\operatorname{Tn} 1546$, were present in strains of canine origin which were all susceptible to vancomycin. This could be explained by possible mutations or deletions within this transposon causing the susceptible phenotype in canine isolates. Because the association between ampicillin and vancomycin resistance phenotypes in humans probably reflects sequential and independent acquisition of resistance genes resulting in the selective dominance of a small subset of hospital-adapted clones (Willems et al., 2011), care should be taken to completly withdraw vancomycin from veterinary medicine and to perform detailed surveillance studies on possible anthropo-zoonotic transfer of ARE.

In this study, the high-level ciprofloxacin and ampicillin resistances observed were associated respectively with previously reported amino acid changes in topoisomerase IV, DNA gyrase 
and in PBP5 (Ligozzi et al., 1996; Zorzi et al., 1996; Rice et al., 2001; Jureen et al., 2003; Werner et al., 2010). To our knowledge, previous studies did not observe mutations in the gyrB target (Leavis et al., 2006; Werner et al., 2010; Valdezate et al., 2012). The contribution of these amino acid changes in GyrB to ciprofloxacin resistance is difficult to evaluate because amino acid changes in GyrA and ParC alone are sufficient to confer high-level resistance to ciprofloxacin. Other resistance mechanisms may be responsible for (low-level) ciprofloxacin resistance in HA ARE isolates that do not contain amino acid changes in the QRDRs of ParC and GyrA. Recently, characterization of EfmA, a multidrug efflux pump conferring resistance to quinolones and macrolides, from E. faecium has been described (Nishioka et al., 2009) which could explain low-level ciprofloxacin resistance in some of the isolates of this study.

So far, canine ARE have been shown to carry fewer virulence traits (De Regt et al., 2012; Kwon et al., 2012) compared to human HA ARE (Top et al., 2008; Werner et al., 2010). It was also shown in a recent report that canine E. faecium did not form biofilms and lacked the strong gelatinase phenotype as well as esp (Ghosh et al., 2011). Also, as observed in our study, ARE strains that colonize the gastrointestinal tract of humans have been shown to carry less determinants such as the enterococcal surface protein, Esp (Coque et al., 2002; Heikens et al., 2007), genomic islands (Heikens et al., 2008), and insertion sequence elements (Leavis et al., 2007). Recently, a sequence-based classification system for enterococcal plasmids has been established which targets replicon-specific plasmid DNA to determine 19 plasmid families which are associated with either a very narrow or a broader host range (Jensen et al., 2010). This procedure was attempted to determine whether specific plasmid families were involved in ARE of canine origin vs. human origin. In this study, rep 6 (small cryptic plasmids) and rep $p_{11}$ (toxin producing plasmids) plasmid families were significantly associated with isolates from dogs. Interestingly, it was also observed that these two families seem to be associated with human isolates from colonization (CCRI no. 18581, 16717, and 16354) but due to low number of isolates this statistical significance could not be addressed. No significant association between rep families and antimicrobial resistance genes could be identified for isolates of canine origin whereas the human clinical strains were significantly associated $(p<0.05)$ with $\mathrm{erm}(\mathrm{B}) / \mathrm{erm}(\mathrm{AM})$, aadE, sat(4), aph(3')-IIIa, IS1182 and with the repp plasmid

\section{REFERENCES}

Aarestrup, F. M. (2000). Characterization of glycopeptideresistant Enterococcus faecium (GRE) from broilers and pigs in Denmark: genetic evidence that persistence of GRE in pig herds is associated with coselection by resistance to macrolides. J. Clin. Microbiol. 38, 2774-2777.

Aarestrup, F. M., Hasman, H., Jensen, L. B., Moreno, M., Herrero, I. A., Dominguez, L., et al. (2002). Antimicrobial resistance among enterococci from pigs in three European countries. Appl. Environ.
Microbiol. 68, 4127-4129. doi: 10.1128/AEM.68.8.4127-4129.2002

Anonymous. (2008). "Programme intégré canadien de surveillance de la résistance aux antimicrobiens (PICRA)". Guelph, ON: Agence de la santé publique du Canada

Billstrom, H., Lund, B., Sullivan, A., and Nord, C. E. (2008). Virulence and antimicrobial resistance in clinical Enterococcus faecium. Int. J. Antimicrob. Agents 32, 374-377. doi: $\quad 10.1016 /$ j.ijantimicag.2008. 04.026

Champagne, J., Diarra, M. S., Rempel, H., Topp, E., Greer, C. W., Harel,

family which has been previously reported (Grady and Hayes, 2003). Interestingly, these genes were also detected in a surveillance human isolate. Recently, a significant correlation between the absence of CRISPR-cas loci and the presence of antibioticresistance genes was previously described for E. faecalis (Palmer and Gilmore, 2010). This tendency was also observed in ARE of this study but due to the low number of isolates its significance could not be determined. Further research is needed to assess the virulence and the antimicrobial resistance of canine strains in comparison with that of human strains and, more generally, to quantify the magnitude of this possible emerging zoonotic problem.

In conclusion, the current study provides the first characterization of canine clinical ARE isolates in Canada with STs identical or closely related to human clinical isolates. This analysis, as well as previous reports, further indicates that canine ARE isolates are evolutionarily linked with hospital ARE isolates with some discordance in their multi-drug resistance and virulence attributes. These findings also support the importance of prudent use of antibiotics in veterinary medicine to avoid zoonotic spread and development of vancomycin resistance of canine ARE isolates. Select and spread of HA-strains that can cause human infections is a major concern, independently of being VRE, because in some countries ARE associated with human infections remain vancomycin susceptible. Further studies are needed to understand the significance of dogs in the spread of this nosocomial pathogen in the community. The occurrence of ARE in dogs and other domestic animals could be addressed by national programs in order to explore the importance of the animal reservoir in the evolution of human hospital ARE isolates.

\section{ACKNOWLEDGMENTS}

This work was funded partly by grants from the Natural Sciences and Engineering Research Council of Canada (M. Archambault, RGPIN-191461) and the Public Health Agency of Canada (in kind). We want to thank Dr. Maurice Boissinot from the Research Center of Laval University for providing human clinical isolates. We want to thank the Diagnostic Laboratory at the Faculty of Veterinary Medicine of University of Montreal to provide animal clinical isolates. We also thank Guy Beauchamp at the Faculty of Veterinary Medicine of University of Montreal for his help in statistical analysis.

J., et al. (2011). Development of a DNA microarray for enterococcal species, virulence, and antibiotic resistance gene determinations among isolates from poultry. Appl. Environ. Microbiol. 77, 2625-2633. doi: 10.1128/AEM.00263-11

Clinical and Laboratory Standards Institute. (2008). Performance standards for antimicrobial disk and dilution susceptibility tests for bacteria isolated from animals. Approved standard-third edition. CLSI Doc. M31-A3 28, 1-99.

Clinical and Laboratory Standards Institute. (2010). Performance standards for antimicrobial susceptibility testing; Approved standard- twentieth informational supplement. CLSI Doc. M100-S20 31, 76-79.

Coque, T. M., Willems, R., Canton, R., Del Campo, R., and Baquero, F. (2002). High occurrence of esp among ampicillin-resistant and vancomycin-susceptible Enterococcus faecium clones from hospitalized patients. J. Antimicrob. Chemother. 50, 1035-1038. doi: 10.1093/jac/dkf229

Damborg, P., Sorensen, A. H., and Guardabassi, L. (2008). Monitoring 
of antimicrobial resistance in healthy dogs: first report of canine ampicillin-resistant Enterococcus faecium clonal complex 17. Vet. Microbiol. 132, 190-196. doi: 10.1016/j.vetmic.2008.04.026

Damborg, P., Top, J., Hendrickx, A. P., Dawson, S., Willems, R. J., and Guardabassi, L. (2009). Dogs are a reservoir of ampicillin-resistant Enterococcus faecium lineages associated with human infections. Appl. Environ. Microbiol. 75, 2360-2365. doi: 10.1128/AEM. 02035-08

De Leener, E., Martel, A., Decostere, A., and Haesebrouck, F. (2004). Distribution of the erm (B) gene, tetracycline resistance genes, and Tn1545-like transposons in macrolide- and lincosamideresistant enterococci from pigs and humans. Microb. Drug Resist. 10, 341-345. doi: 10.1089/mdr.2004. 10.341

De Regt, M. J., Van Der Wagen, L. E., Top, J., Blok, H. E., Hopmans, T. E., Dekker, A. W., et al. (2008). High acquisition and environmental contamination rates of $\mathrm{CC} 17$ ampicillin-resistant Enterococcus faecium in a Dutch hospital. J. Antimicrob. Chemother. 62, 1401-1406. doi: 10.1093/jac/dkn390

De Regt, M. J., Van Schaik, W., Van Luit-Asbroek, M., Dekker, H. A., Van Duijkeren, E., Koning, C. J., et al. (2012). Hospital and community ampicillin-resistant Enterococcus faecium are evolutionarily closely linked but have diversified through niche adaptation. PLoS ONE 7:e30319. doi: 10.1371/journal.pone.0030319

Diarra, M. S., Rempel, H., Champagne, J., Masson, L., Pritchard, J., and Topp, E. (2010). Distribution of antimicrobial resistance and virulence genes in Enterococcus spp. and characterization of isolates from broiler chickens. Appl. Environ. Microbiol. 76, 8033-8043. doi: 10.1128/AEM. 01545-10

Garcia-Migura, L., Pleydell, E., Barnes, S., Davies, R. H., and Liebana, E. (2005). Characterization of vancomycin-resistant Enterococcus faecium isolates from broiler poultry and pig farms in England and Wales. J. Clin. Microbiol. 43, 3283-3289. doi: 10.1128/JCM.43.7.3283-3289.2005

Ghosh, A., Dowd, S. E., and Zurek, L. (2011). Dogs leaving the ICU carry a very large multi-drug resistant enterococcal population with capacity for biofilm formation and horizontal gene transfer. PLoS ONE 6:e22451. doi: 10.1371/journal.pone.0022451

Grady, R., and Hayes, F. (2003). AxeTxe, a broad-spectrum proteic toxin-antitoxin system specified by a multidrug-resistant, clinical isolate of Enterococcus faecium. Mol. Microbiol. 47, 1419-1432. doi: 10.1046/j.1365-2958.2003.03387.x

Grayson, M. L., Eliopoulos, G. M., Wennersten, C. B., Ruoff, K. L., De Girolami, P. C., Ferraro, M. J., et al., (1991). Increasing resistance to beta-lactam antibiotics among clinical isolates of Enterococcus faecium: a 22 -year review at one institution. Antimicrob. Agents Chemother. 35, 2180-2184. doi: 10.1128/AAC.35.11.2180

Heikens, E., Bonten, M. J., and Willems, R. J. (2007). Enterococcal surface protein Esp is important for biofilm formation of Enterococcus faecium E1162. J. Bacteriol. 189, 8233-8240. doi: 10.1128/JB.01205-07

Heikens, E., Van Schaik, W., Leavis, H. L., Bonten, M. J., and Willems, R. J. (2008). Identification of a novel genomic island specific to hospital-acquired clonal complex 17 Enterococcus faecium isolates. Appl. Environ. Microbiol. 74, 7094-7097. doi: 10.1128/AEM. 01378-08

Iwen, P. C., Kelly, D. M., Linder, J., Hinrichs, S. H., Dominguez, E. A., Rupp, M. E., et al. (1997). Change in prevalence and antibiotic resistance of Enterococcus species isolated from blood cultures over an 8-year period. Antimicrob. Agents Chemother. 41, 494-495.

Jackson, C. R., Fedorka-Cray, P. J., Davis, J. A., Barrett, J. B., and Frye, J. G. (2009). Prevalence, species distribution and antimicrobial resistance of enterococci isolated from $\operatorname{dogs}$ and cats in the United States. J. Appl. Microbiol. 107, 1269-1278. doi: 10.1111/j.1365-2672.2009.04310.x

Jensen, L. B., Garcia-Migura, L., Valenzuela, A. J., Lohr, M., Hasman, H., and Aarestrup, F. M. (2010). A classification system for plasmids from enterococci and other Gram-positive bacteria. J. Microbiol. Methods 80, 25-43. doi: 10.1016/j.mimet.2009.10.012

Jureen, R., Top, J., Mohn, S. C., Harthug, S., Langeland, N., and Willems, R. J. (2003). Molecular characterization of ampicillin-resistant Enterococcus faecium isolates from hospitalized patients in Norway. J. Clin. Microbiol. 41, 2330-2336. doi: 10.1128/JCM.41.6.2330-2336.2003
Kwon, K. H., Moon, B. Y., Hwang, S. Y., and Park, Y. H. (2012). Detection of CC17 Enterococcus faecium in Dogs and a Comparison with Human Isolates. Zoonoses Public Health 59, 375-378. doi: 10.1111/j.1863-2378.2012.01466.x

Leavis, H. L., Willems, R. J., Top, J., and Bonten, M. J. (2006). Highlevel ciprofloxacin resistance from point mutations in gyrA and parC confined to global hospitaladapted clonal lineage $\mathrm{CC} 17$ of Enterococcus faecium. J. Clin Microbiol. 44, 1059-1064. doi 10.1128/JCM.44.3.1059-1064.2006

Leavis, H. L., Willems, R. J., Van Wamel, W. J., Schuren, F. H., Caspers, M. P., and Bonten, M. J. (2007). Insertion sequence-driven diversification creates a globally dispersed emerging multiresistant subspecies of E. faecium. PLoS Pathog. 3:e7. doi 10.1371/journal.ppat.0030007

Ligozzi, M., Pittaluga, F., and Fontana, R. (1996). Modification of penicillin-binding protein 5 associated with high-level ampicillin resistance in Enterococcus faecium. Antimicrob. Agents Chemother. 40, 354-357.

McCracken, M., Wong, A., Mitchell, R., Gravel, D., Conly, J., Embil, J., et al. (2013). Molecular epidemiology of vancomycin-resistant enterococcal bacteraemia: results from the Canadian Nosocomial Infection Surveillance Program, 1999-2009. J. Antimicrob. Chemother. 68, 1505-1509. doi: 10.1093/jac/dkt054 Nallapareddy, S. R., Weinstock, G. M. and Murray, B. E. (2003). Clinical isolates of Enterococcus faecium exhibit strain-specific collagen binding mediated by Acm, a new member of the MSCRAMM family. Mol. Microbiol. 47, 1733-1747. doi: $\quad 10.1046 / j .1365-2958.2003$ 03417.x

Nishioka, T., Ogawa, W., Kuroda, T., Katsu, T., and Tsuchiya, T. (2009). Gene cloning and characterization of EfmA, a multidrug efflux pump, from Enterococcus faecium. Biol. Pharm. Bull. 32, 483-488. doi 10.1248/bpb.32.483

Ossiprandi, M. C., Bottarelli, E., Cattabiani, F., and Bianchi, E. (2008). Susceptibility to vancomycin and other antibiotics of 165 Enterococcus strains isolated from dogs in Italy. Comp. Immunol. Microbiol. Infect. Dis. 31, 1-9. doi: 10.1016/j.cimid.2007.08.003

Palmer, K. L., and Gilmore, M. S. (2010). Multidrug-resistant enterococci lack CRISPR-cas. MBio 1:e00227-10. doi: $10.1128 / \mathrm{mBio}$. 00227-10
Poeta, P., Costa, D., Igrejas, G., Saenz, Y., Zarazaga, M., Rodrigues, J., et al. (2007). Polymorphisms of the pbp5 gene and correlation with ampicillin resistance in Enterococcus faecium isolates of animal origin. J. Med. Microbiol. 56, 236-240. doi: 10.1099/jmm.0.46778-0

Poeta, P., Costa, D., Rodrigues, J., and Torres, C. (2005). Antimicrobial resistance and the mechanisms implicated in faecal enterococci from healthy humans, poultry and pets in Portugal. Int. J. Antimicrob. Agents 27, 131-137. doi: 10.1016/ j.ijantimicag.2005.09.018

Rice, L. B., Carias, L. L., HuttonThomas, R., Sifaoui, F., Gutmann, L., and Rudin, S. D. (2001). Penicillin-binding protein 5 and expression of ampicillin resistance in Enterococcus faecium. Antimicrob. Agents Chemother. 45, 1480-1486. doi: 10.1128/AAC.45.5.1480-1486. 2001

Roberts, M. C., Sutcliffe, J., Courvalin, P., Jensen, L. B., Rood, J., and Seppala, H. (1999). Nomenclature for macrolide and macrolidelincosamide-streptogramin B resistance determinants. Antimicrob Agents Chemother. 43, 2823-2830.

Seno, Y., Kariyama, R., Mitsuhata, R., Monden, K., and Kumon, H. (2005). Clinical implications of biofilm formation by Enterococcus faecalis in the urinary tract. Acta Med. Okayama 59, 79-87.

Simjee, S., White, D. G., McDermott, P. F., Wagner, D. D., Zervos, M. J., Donabedian, S. M., et al. (2002). Characterization of Tn1546 in vancomycin-resistant Enterococcus faecium isolated from canine urinary tract infections: evidence of gene exchange between human and animal enterococci. J. Clin. Microbiol. 40, 4659-4665. doi: 10.1128/JCM.40. 12.4659-4665.2002

Stepanovic, S., Vukovic, D., Dakic, I., Savic, B., and Svabic-Vlahovic, M. (2000). A modified microtiterplate test for quantification of staphylococcal biofilm formation. J. Microbiol. Methods 40, 175-179. doi: $\quad 10.1016 / S 0167-7012(00)$ 00122-6

Stepanovic, S., Vukovic, D., Hola, V., Di Bonaventura, G., Djukic, S., Cirkovic, I., et al. (2007) Quantification of biofilm in microtiter plates: overview of testing conditions and practical recommendations for assessment of biofilm production by staphylococci. APMIS 115, 891-899. doi: 10.1111/j.16000463.2007.apm_630.x 
Top, J., Willems, R., and Bonten, M. (2008). Emergence of CC17 Enterococcus faecium: from commensal to hospital-adapted pathogen. FEMS Immunol. Med. Microbiol. 52, 297-308. doi: 10.1111/j.1574-695X.2008.00383.x

Tremblay, C. L., Letellier, A., Quessy, S., Boulianne, M., Daignault, D., and Archambault, M. (2011). Multiple-antibiotic resistance of Enterococcus faecalis and Enterococcus faecium from cecal contents in broiler chicken and turkey flocks slaughtered in Canada and Plasmid Colocalization of tetO and ermB Genes. J. Food Prot. 74, 1639-1648. doi: 10.4315/0362-028X.JFP-10-451

Tremblay, C. L., Letellier, A., Quessy, S., Daignault, D., and Archambault, M. (2012). Antibiotic-resistant Enterococcus faecalis in abattoir pigs and plasmid colocalization and cotransfer of tet(M) and erm(B) genes. J. Food Prot. 75, 1595-1602. doi:

10.4315/0362-028X JFP-12-047

Valdezate, S., Miranda, C., Navarro, A., Freitas, A. R., Cabrera, J. J., Carrasco, G., et al. (2012). Clonal outbreak of ST17 multidrug-resistant Enterococcus faecium harbouring an Inc18like::Tn1546 plasmid in a haemo-oncology ward of a Spanish hospital. J. Antimicrob. Chemother. 67, 832-836. doi: 10.1093/jac/dkr545

Van Schaik, W., and Willems, R. J. (2010). Genome-based insights into the evolution of enterococci. Clin. Microbiol. Infect. 16, 527-532. doi: 10.1111/j.1469-0691.2010.03201.x

Van Schaik, W., Top, J., Riley, D. R., Boekhorst, J., Vrijenhoek, J. E., Schapendonk, C. M., et al (2010). Pyrosequencing-based comparative genome analysis of the nosocomial pathogen Enterococcus faecium and identification of a large transferable pathogenicity island. BMC Genomics 11:239. doi: 10.1186/1471-2164-11-239

Vankerckhoven, V., Huys, G., Vancanneyt, M., Snauwaert, C. Swings, J., Klare, I., et al. (2008). Genotypic diversity, antimicrobial resistance, and virulence factors of human isolates and probiotic cultures constituting two intraspecific groups of Enterococcus faecium isolates. Appl. Environ. Microbiol. 74, 4247-4255. doi: 10.1128/AEM.02474-07

Vankerckhoven, V., Van Autgaerden, T., Vael, C., Lammens, C., Chapelle, S., Rossi, R., et al. (2004). Development of a multiplex PCR for the detection of asal, gelE, cylA, esp, and hyl genes in enterococci and survey for virulence determinants among European hospital isolates of Enterococcus faecium. J. Clin. Microbiol. 42, 4473-4479. doi: 10.1128/JCM.42.10.4473-4479.2004

Werner, G., Fleige, C., Ewert, B. Laverde-Gomez, J. A., Klare, I., and Witte, W. (2010). High-level ciprofloxacin resistance among hospital-adapted Enterococcus faecium (CC17). Int. J. Antimicrob.
Agents 35, 119-125. doi: 10.1016/j.ijantimicag.2009.10.012

Werner, G., Fleige, C., Geringer, U. Van Schaik, W., Klare, I., and Witte, W. (2011). IS element IS16 as a molecular screening tool to identify hospital-associated strains of Enterococcus faecium. BMC Infect. Dis. 11:80. doi: 10.1186/1471-2334-11-80

Willems, R. J., and Van Schaik, W. (2009). Transition of Enterococcus faecium from commensal organism to nosocomial pathogen. Future Microbiol. 4, 1125-1135. doi: 10.2217/fmb.09.82

Willems, R. J., Hanage, W. P., Bessen, D. E., and Feil, E. J. (2011). Population biology of gram-positive pathogens: high-risk clones for dissemination of antibiotic resistance. FEMS Microbiol. Rev. 35, 872-900. doi: 10.1111/j.1574-6976.2011.00284.x

Willems, R. J., Top, J., Van Schaik, W., Leavis, H., Bonten, M., Siren, J., et al. (2012). Restricted gene flow among hospital subpopulations of Enterococcus faecium. MBio 3:e00151-00112. doi: 10.1128/mBio.00151-12

Zoletti, G. O., Pereira, E. M., Schuenck, R. P., Teixeira, L. M., Siqueira, J. F. Jr., et al. (2011). Characterization of virulence factors and clonal diversity of Enterococcus faecalis isolates from treated dental root canals. Res. Microbiol. 162, 151-158. doi: 10.1016/j.resmic.2010.09.018

Zorzi, W., Zhou, X. Y., Dardenne, O., Lamotte, J., Raze, D., Pierre, J., et al. (1996). Structure of the low-affinity penicillin-binding protein 5 PBP5 $\mathrm{fm}$ in wild-type and highly penicillin-resistant strains of Enterococcus faecium. J. Bacteriol. 178, 4948-4957.

Conflict of Interest Statement: The authors declare that the research was conducted in the absence of any commercial or financial relationships that could be construed as a potential conflict of interest.

Received: 15 March 2013; accepted: 05 August 2013; published online: 23 August 2013

Citation: Tremblay C-L, Charlebois A, Masson $L$ and Archambault $M$ (2013) Characterization of hospitalassociated lineages of ampicillin-resistant Enterococcus faecium from clinical cases in dogs and humans. Front. Microbiol. 4:245. doi: 10.3389/fmicb.2013.00245 This article was submitted to Antimicrobials, Resistance and Chemotherapy, a section of the journal Frontiers in Microbiology.

Copyright (C) 2013 Tremblay, Charlebois, Masson and Archambault. This is an open-access article distributed under the terms of the Creative Commons Attribution License (CC BY). The use, distribution or reproduction in other forums is permitted, provided the original author(s) or licensor are credited and that the original publication in this journal is cited, in accordance with accepted academic practice. No use, distribution or reproduction is permitted which does not comply with these terms. 